\title{
EFFECT OF SEGMENTATION AND USER CONTROL ON LEARNING OF BASIC SURGICAL SKILLS
}

\author{
Afifa Tabassum ${ }^{1,2 \otimes}$, Masood Jawaid $^{3}$
}

\begin{abstract}
OBJECTIVE: To assess the effect of segmentation and user control on learning of basic surgical skills in a video-based instruction format as compared to nonsegmented video-based instruction format in novices.

METHODS: This quasi-experimental study was conducted at Dow University of health sciences Karachi, Pakistan. Sixty students were divided into four groups of 15 each. Each group had a different method of instruction. Group A: nonsegmentation with facilitator; Group B: non-segmentation without facilitator; Group C: segmentation with no user control; Group D: segmentation with user control. All groups' knot tying skill was assessed at the end of session. Data analyzed using SPSS version- 17. Kruskal Wallis and Mann-Whitney $U$ tests were applied for data analysis.
\end{abstract}

RESULTS: Out of 60 participants, sixteen $(26.7 \%)$ were male and forty-four $(73.3 \%)$ were female. Overall, scores on performance examination $[p=0.006]$ were statistically significant. With respect to method of instruction, scores on performance examinations of group $A$ and group $B$ were statistically significant $[D(I 5)=0.300, p=0.00 I]$ and $[D(I 5)=0.225, p=0.040]$ respectively. Levine test was employed to assess the homogeneity of variance assumption. For performance scores, the variances were equal for all four group students (i.e. nonsignificant) $[F(3,56)=1.68, p=0.182]$ and $[F(3,56)=1.90, p=0.140]$ respectively]. Median performance scores were significantly higher in group $A$ as compared to group $D[U=45.50, r=-0.73, p=0.004]$.

CONCLUSION: Non-segmented video-based instructions with expert feedback result in increased learning of basic surgical as compared to segmentation with user control, in novice students. Both segmented and nonsegmented video resulted in similar amount of learning.

KEY WORDS: Segmentation (Non-MeSH); User control (Non-MeSH); Medical skills training (Non-MeSH)

THIS ARTICLE MAY BE CITED AS: Tabassum A, Jawaid M. Effect of segmentation and user control on learning of basic surgical skills. Khyber Med Univ J 2020; I 2(4): 294-8. DOI: I0.35845/kmuj.2020.19977.

\section{INTRODUCTION}

E ducation has undergone a significant change in the past few decades. Technology is now becoming an integral part of learning experience and is increasingly being used in instruction.' Simple modalities like images, audio/video files and animations are available alongside high-fidelity simulations like laparoscopic simulators etc. This change has also been adopted in the training of medical or surgical/procedural skills. Videos are being widely used in medicine as part of training of clinical procedural skills like Basic Surgical Skills, Basic Life Support, Advanced Cardiac Life Support etc. ${ }^{2-4}$ The efficacy of video-based training can be explained by the fact that a combination of viewing the expert demonstration and actually performing the skill enhances learning by helping student to get the feel of the skill resulting in enhanced performance. ${ }^{5}$

It has been observed that when videos are used for learning of skills/ procedures they lead to an increase in the cognitive load. ${ }^{6}$ Some effective means that have been developed to
I. Professional Development Centre, Dow University of Health Sciences, Karachi, Pakistan.

2 Liaquat National Hospital, Karachi, Pakistan.

3 Darul Sehat Hospital, Liaquat College of Medicine and Dentistry, Karachi, Pakistan.

Email区: dr.afifa@ymail.com

Contact \#: +92-334-2818170

Date Submitted:

December 24, 2019

Date Revised:

October 15, 2020

Date Accepted: October 21,2020

decrease this load in video instruction format are cueing (providing prompts to the learner on how to select and organize the learning material), visual grouping (grouping of similar information into smaller units) and segmentation (showing animations and videos in segments). ${ }^{7}$ Studies observing the effect of segmentation mostly in area of multimedia instruction and in the domain of cognitive knowledge suggests that segmented animations are more effective than non-segmented animations in improving learning especially in novices.

Learner control is another strategy that has been found to influence learning by decreasing cognitive load. ${ }^{8,9}$ Studies showed that the ability to stop, forward or rewind enabled learners to learn at their own pace and according to their cognitive needs.6 Aspects of learner control include pacing, content, sequence and decisions about what sections to study. ${ }^{10}$

There are very few studies studying this effect on video-based instruction and that too in teaching medical procedural skills. But the available literature shows that some type of user control like control over speed and repetition resulted in better performance. II Similar results have been noted when these strategies have been applied to teaching procedural skills to medical students. $^{12,13}$ 
TABLE I: COMPARISON OF PERFORMANCE SCORES TO METHOD OF INSTRUCTION

\begin{tabular}{|l|c|c|c|}
\hline \multicolumn{1}{|c|}{ Method of instruction } & Median Score & Inter-quartile Range & p-value* \\
\hline $\begin{array}{l}\text { Group A } \\
\text { (No segmentation with facilitator) }\end{array}$ & 08 & $7-9$ & \multirow{2}{*}{0.007} \\
\hline $\begin{array}{l}\text { Group B } \\
\text { (No segmentation without facilitator) }\end{array}$ & 06 & $4-7$ & $6-8$ \\
\hline $\begin{array}{l}\text { Group C } \\
\text { (Segmentation without user control) }\end{array}$ & 07 & $5-7$ & \\
\hline $\begin{array}{l}\text { Group D } \\
\text { (Segmentation with user control) }\end{array}$ & 06 & 06 & \\
*Using Kruskal-Wallis test with p value $<0.05$ as statistically significant, df=3, test statistics= 12.06 &
\end{tabular}

TABLE II: POST-HOC ANALYSES AND EFFECT SIZE ESTIMATION OF PERFORMANCE SCORES BASED ON METHOD OF INSTRUCTION

\begin{tabular}{|l|c|c|c|c|}
\hline \multicolumn{2}{|c|}{ Group comparison } & Statistics & Effect size (r) & p-value* \\
\hline \multirow{4}{*}{$\begin{array}{l}\text { Performance } \\
\text { scores }\end{array}$} & Group A versus group B & 58.50 & -0.59 & 0.023 \\
\cline { 2 - 5 } & Group A versus group C & 70.50 & -0.46 & 0.081 \\
\cline { 2 - 5 } & Group A versus group D & 45.50 & -0.73 & 0.004 \\
\cline { 2 - 5 } & Group B versus group C & 75.00 & -0.28 & 0.113 \\
\cline { 2 - 5 } & Group B versus group D & 93.00 & -0.15 & 0.412 \\
\cline { 2 - 5 } & Group C versus group D & 86.00 & -0.21 & 0.263 \\
\hline
\end{tabular}

*Using Mann-Whitney $\mathrm{U}$ test taking $\mathrm{p}$-value $<0.0083$ as statistical significance (after Bonferroni correction).
Group $\mathrm{A}=$ No segmentation with facilitator, Group $\mathrm{B}=$ No segmentation without facilitator Group $\mathrm{C}=$ Segmentation without user control, Group $\mathrm{D}=$ Segmentation with user control

Based on results of previous research, ${ }^{12,13}$ we hypothesized that learners may benefit more from an instructional design comprising of segmentation of videos (with user control) rather than continuous video.

\section{METHODS}

This study was conducted at Dow University of health sciences, Karachi, Pakistan, from 2014-2015. The study design was quasi-experimental. After institutional review board (IRB) approval Sixty (60) third year medical students were selected by nonprobability, convenience sampling. All third-year students posted in department of surgery were included. Students who refused to be part of the study and those who had prior knowledge of tying surgical knots were excluded from the study. The purpose of the study was explained to participants and verbal consent was taken.

Students were divided into four groups of I 5 each. Each group was subjected to a different method of instruction:

GROUP A (NON-SEGMENTED
WITH FACILITATOR, NO USER CONTROL)- students reviewed the non-segmented video and practiced tying a one-handed reef knot. Instructor was present to facilitate the process. The expert instructor answered questions and gave performance feedback as necessary. Demonstrations by the expert were permitted.

\section{GROUP B (NON-SEGMENTED WITHOUT FACILITATOR, NO USER CONTROL) - students} reviewed the non-segmented video and practiced tying a one-handed reef knot. Instructor was not present; hence participants did not receive any feedback.

GROUP C (SEGMENTATION WITH NO USER CONTROL)students reviewed the segmented video with programmed pauses. After the pauses, the video segments continued automatically. Students practiced during the pauses.

GROUP D (SEGMENTATION WITH USER CONTROL) - students reviewed the same segmented video as group $C$ but with the option of pause, play and repeat. Each participant was given a separate computer equipped with a headset. We instructed the participants on how to navigate in the videos and that they could watch the videos as many times as they liked within the given time period.

The video used in this study is a standard video used in the Basic Surgical Skills course by Royal College of Surgeons. For training session of groups 3 and 4, this video was segmented using Camtasia. The duration of segments and the moment of the segment endings were determined by surgeons who were master trainers of Basic Surgical Skills Course. The knotting board used is a standard training board used in basic surgical skills courses.

The participants practiced according to the training condition assigned to them on the standard training knotting boards. All groups were given twenty minutes to practice. The time duration was chosen by surgical experts. All groups were assessed immediately at the end of session on a performance checklist by Basic Surgical Skills experts. The checklist consisted of 4 components of the knot-tying skill: Thread grasp, first hitch, second hitch, finished knot. The maximum achievable score was I 3 .

Data was analyzed by using SPSS version-17. Descriptive statistics: mean and standard deviation computed for quantitative output response. Statistical assumptions were evaluated using statistical tests. Alpha was set at 0.05 for all statistical tests, Bonferroni adjustments were made when conducting multiple tests. Nonparametric test, Kruskal Wallis, was used to demonstrate statistical significance of data set. Mann-Whitney $U$ tests was used for post-hoc analysis.

\section{RESULTS}

Out of 60 participants, sixteen $(26.7 \%)$ were male and forty-four (73.3\%) were female. Since the sample was small, assumptions of parametric test were examined that included KolomogorovSmirnov test and Levine test. Kolomogorov-Smirnov test was executed to determine the normality assumption of data set. Overall, scores on performance examination 
$[p=0.006]$ were statistically significant. With respect to method of instruction, scores on performance examinations of group A (no segmentation with facilitator) and group $B$ (no segmentation without facilitator) were statistically significant $[D(I 5)=0.300$, $\mathrm{p}=0.00 \mathrm{I}]$ and $[\mathrm{D}(\mathrm{I} 5)=0.225$, $p=0.040]$ respectively. Levine test was employed to assess the homogeneity of variance assumption. For performance scores, the variances were equal for all four group students (i.e. non-significant) $[F(3,56)=1.68, p=0.182]$ and $[F(3,56)$ $=1.90, p=0.140]$ respectively].

As most of the parametric assumptions were not satisfied, Kruskal Wallis was used to demonstrate statistical significance of data set. There were statistically significant differences amongst median performance scores by different methods of instruction $[\mathrm{H}(3)$ $=$ I2.06, $\mathrm{p}=0.007$ ] (Table l).

In order to determine which method of instruction was responsible for this difference, Mann-Whitney $U$ tests (as post-hoc analysis) were used to followup this finding. A Bonferroni correction was applied and so all effects were reported at or less than a 0.0083 level of significance (Table-II).

It appeared that median performance scores were significantly higher in group A (no segmentation with facilitator) as compared to group $D$ (segmentation with user control) $[U=45.50, r=-0.73$, $\mathrm{p}=0.004]$.

\section{DISCUSSION}

In this study it was hypothesized that segmentation and user control would decrease extraneous load on memory and thus improve performance. The results of the study showed no statistically significant differences in performance scores among groups $A$ (no segmentation with facilitator), Group B (No segmentation without facilitator) and Group C (Segmentation without user control) and between groups B, C and D (Segmentation with user control).

The only significant difference noted was between the group $A$ (no user control and receiving facilitator feedback) and group D (with user control but no feedback). Several reasons may account for these observations. When learning new psychomotor skills, participants use two types of feedback to assess their performance: internal and external. Internal feedback is generated when students assess their own performance visually and are able identify the differences between their and the expert's performance. External feedback is usually given by an expert. ${ }^{14}$ In this study the group that received external feedback had a significantly higher performance score. This may be because the students were novices and the skills were moderately complex. Internal feedback enabled the learners to recognize the differences in their performance and expert performance, but expert feedback was required to identify and correct their errors.

The effect of expert feedback was studied by Xeroulis G, et al. ${ }^{12}$ Junior medical students learnt suturing and knot-tying skills through self-directed video training. A computer-generated feedback was given to Group A, expert reference values along with computer feedback was given to Group B and an expert gave feedback to Group C. Results demonstrated that the group receiving expert feedback retained the skill better as compared to other groups. This agrees with a study by Rogers D, et al. ${ }^{14}$ in which computerbased learning in combination with external feedback, resulted in a higher level of expertise of 2-handed knottying in novices as compared to computer-based learning alone.

The second element that differed among the two groups was user control. The fact that user control did not result in significant improvement in performance as compared to non-user control may be the result of student characteristics. Literature suggests that user control may be more beneficial in learners with prior knowledge of task than novices as they have better conceptual understanding of the content and they are better aware of their instructional progress and if they need further instruction or not ${ }^{8}$.
Fry $\mathrm{JP}^{15}$ in a study demonstrated that students who had a high aptitude for the domain being taught, benefitted significantly better from learner control. Studies in cognitive domain with similar results were conducted by several other researchers. ${ }^{7-9}$ The study on effect of user control on procedural knowledge indicated that overall students appear to benefit from learner control opportunities, but it was also evident that greatest benefit was derived by learners who had higher content domain experience. 16 But not all studies corroborate with our results. Jowett $\mathrm{N}$, et al. ${ }^{17}$ found that Computer Based Video Training for the I-handed square knot was effective in a selfdirected learning environment among novices. Schwan and Riempp studied the effects of user interactivity in the acquisition of knowledge through video-based instruction. Interaction with the presentations led to more rapid acquisition of knowledge of knot tying."

Another reason that user control did not result in significant improvement in performance may be that the participants were third year students who are not used to self-directed study method. Self-directed study is a skill that needs to be taught and develops through a process of directed selfguidance. $^{13,18}$

In this study, both segmented and nonsegmented video resulted in similar amount of learning. Literature suggests that in any given simulation there is a maximum quantity of information that may be transferred to a learner and once this threshold is reached, further learning does not occur. In this study segmentation of the video did not improve skill learning as the skill was moderately difficult and the video may have contained enough information for optimum learning to occur within the given time period. ${ }^{19}$ These results are comparable to a study by Janda MS, et al. in which similar learning and retention of skills occurred in both nonsegmented and segmented video based learning in dental students. ${ }^{20}$ In addition, training with non-interactive video was as effective as training with interactive, self-directed video. 
This study was a single centre, nonrandomized study. Our study was limited in having a small sample size which may have influenced the results. Secondly this study assessed the effectiveness of segmentation and user control in the context of only a single basic surgical skill. Furthermore, the transferability of skills gained during these sessions into clinical learning environment was not assessed.

\section{CONCLUSION}

The results of our study support the view that non-segmented video-based instructions with expert feedback result in increased learning of basic surgical as compared to segmentation with user control, in novice students. This study also showed that both segmented and non-segmented video resulted in similar amount of learning. It is not suggested that computer-based training can replace training by an expert, but an appropriately designed computerbased training may facilitate skills training. It will help in efficient use of faculty time and solve scheduling issues in training many students.

\section{ACKNOWLEDGEMENTS}

We would like to thank Dr. Jahanzaib Haider for providing help and expertise in statistical analysis for this study.

\section{REFERENCES}

I. Chandler P. The crucial role of cognitive processes in the design of dynamic visualizations. Learn Instr 2004; 14(3): 353-7. DOI: 10.1016/ j.learninstruc. 2004.06.009.

2. McMaster University. Residents Manual. Basic surgical skills videos. [Accessed on: December 20, 2019]. Available from URL: https://surgery. mcmaster.ca/divisions/neurosurger y/education/residencyprogram/residents-manual/basicsurgical-skills-videos

3. BLS for Healthcare Providers Classroom, Features. [Accessed on: March 30, 2019]. Available from URL: http://www.heart.org/ HEARTORG/CPRAndECC/BLSfor-Healthcare-Providers--Classroom_UCM_303484_Article. jsp http://dse.md/sites/default/ files/image/trilateral_project/Progr am\%20instructori\%20BLS.pdf

4. Advanced Cardiovascular Life Support - Classroom, course format. [Accessed on: April 05, 2019]. Available from URL: http://www.heart.org/HEARTORG /CPRAndECC/HealthcareProviders /AdvancedCardiovascularLifeSupp or t A C L S / A d v a n c e d Cardiovascular-Life-Support--Classroom_UCM_306643_Article. jsp

5. Custers EJ, Regehr G, McCulloch W, Peniston C, Reznick R. The effects of modeling on learning a simple surgical procedure: see one, do one or see many, do one? Adv Health Sci Educ Theory Pract 1999: 4(2); 123 43. DOI: $10.1023 / \mathrm{A}: 10097632$ 10212 .

6. P Wouters, HK Tabbers, F Paas. Interactivity in video-based models. Educ Psychol Rev 2007; 19(3):32742. DOI: $10.1007 / \mathrm{s} \mid 0648-007$ 9045-4.

7. Spanjers IAE, Wouters $P$, van Gog T, van Merriënboer JJG. An expertise reversal effect of segmentation in learning from animated worked-out examples. Comput Hum Behav 20II; 27(I):46-52. DOI: 10.1016/j. chb. 2010.05 .011 .

8. Lawless KA, Brown SW. Multimedia learning environments: Issues of learner control and navigation. Instr Sci | 997;25(2):||7-3|. DOI: I0.1023/A:1002919531780.

9. Kirschner F, Kester L, Corbalan G. Cognitive load theory and multimedia learning, task characteristics, and learning engagement: The current state of the art. Comput Hum Behav 20II Jan I; 27(I): I-4. DOI: 10.1016/j. chb.2010.05.003.

10. Sims R, Hedberg J. Dimensions of Learner Control A Reappraisal for Interactive Multimedia Instruction 1995. [Accessed on: April 05, 20 I 9]. Available from URL: http://citeseerx.ist.psu.edu/viewdo c/summary?doi $=$ I0.1 I.95.99

I I. Schwan S, Riempp R. The cognitive benefits of interactive videos: learning to tie nautical knots. Learn Instr 2004; I4(3): 293-305. DOI: I0.10 |6/j.learninstruc.2004.06.005.

12. Xeroulis GJ, Park J, Moulton CA, Reznick RK, LeBlanc V, Dubrowski A. Teaching suturing and knot-tying skills to medical students: a randomized controlled study comparing computer-based video instruction and (concurrent and summary) expert feedback. Surgery 2007 Apr; I4I (4):442-9. DOI: 10.1016/j.surg.2006.09.012.

13. Brydges R, Carnahan H, Safir O, Dubrowski A. How effective is self-guided learning of clinical technical skills? It's all about process. Med Educ 2009 Jun;43(6):507-15. DOI: $10.1111 /$ j.1365-2923.2009. 03329.x.

14. Rogers DA, Regehr G, Howdieshell TR, Yeh KA, Palm E. The impact of external feedback on computerassisted learning for surgical technical skill training. Am J Surg 2000; I79(4):34I-3. DOI: 10.1016/s 0002-9610(00)0034I-x.

15. Fry JP. Interactive relationship between inquisitiveness and student control of instruction. J Educ Psychol 1972;63(5):459-65. DOI: 10.1037/h0033237.

16. Shyu HY, Brown SW. Learner control: the effects on learning a procedural task during computerbased video instruction. Int J Instr Media 1995;22(3): 2|7-31.

17. Jowett N, LeBlanc V, Xeroulis G, MacRae H, Dubrowski A. Surgical skill acquisition with self-directed practice using computer-based video training. Am J Surg 2007;193(2):237-42. DOI: 10.1016/ j.amjsurg.2006.I I.003.

18. Kaufman DM. ABC of learning and teaching in medicine: Applying educational theory in practice. BMJ 2003;326(7382):2।3-16. DOI: I0.1136/bmj.326.7382.2I3.

19. Nousiainen M, Brydges R, Backstein D, Dubrowski A. Comparison of expert instruction and computerbased video training in teaching fundamental surgical skills to 
medical students. Surgery 2008; I43(4):539-44. DOI: $10.1016 / j$. surg.2007.10.022.

20. Janda MS, Botticelli AT, Mattheos N,
Nebel D, Wagner A, Nattestad A, et al. Computer-mediated instructional video: a randomised controlled trial comparing a sequential and a segmented instructional video in surgical hand wash. Eur J Dent Educ 2005; (2):53 8. DOI: $10.1111 / / \mathrm{j} .1600-0579$ 2004.00366.x.

\section{AUTHORS' CONTRIBUTIONS}

Following authors have made substantial contributions to the manuscript as under:

AT: Conception, acquisition, analysis and interpretation of data, drafting the manuscript, critical review, approval of the final version to be published

MJ: Study design, acquisition of data, drafting the manuscript, critical review, approval of the final version to be published

Authors agree to be accountable for all aspects of the work in ensuring that questions related to the accuracy or integrity of any part of the work are appropriately investigated and resolved.

CONFLICT OF INTEREST
Authors declared no conflict of interest
GRANT SUPPORT AND FINANCIAL DISCLOSURE
NIL

\section{DATA SHARING STATEMENT}

The data that support the findings of this study are available from the corresponding author upon reasonable request. (c) (i) \$ BY NC
This is an Open Access article distributed under the terms of the Creative Commons Attribution-Non Commercial 2.0 Generic License.

\section{KMUJ web address: www.kmuj.kmu.edu.pk}

Email address: kmuj@kmu.edu.pk 